\title{
An Analysis of the Public Perception of Flood Risk on the Belgian Coast
}

Wim Kellens, Ruud Zaalberg, Tijs Neutens, Wouter Vanneuville, Philippe De Maeyer

Published as follows: Kellens, W., R. Zaalberg, T. Neutens, W. Vanneuville and P. De Maeyer (2011). "An Analysis of the Public Perception of Flood Risk on the Belgian Coast." Risk Analysis 31(7): 1055-1068.

\begin{abstract}
In recent years, perception of flood risks has become an important topic to policy makers concerned with risk management and safety issues. Knowledge of the public risk perception is considered a crucial aspect in modern flood risk management as it steers the development of effective and efficient flood mitigation strategies. This study aimed at gaining insight into the perception of flood risks along the Belgian coast. Given the importance of the tourism industry on the Belgian coast, the survey considered both inhabitants and residential tourists. Based on actual expert's risk assessments, a high and a low risk area were selected for the study. Risk perception was assessed on the basis of scaled items regarding storm surges and coastal flood risks. In addition, various personal and residence characteristics were measured. Using multiple regression analysis, risk perception was found to be primarily influenced by actual flood risk estimates, age, gender and experience with previous flood hazards.
\end{abstract}

keywords: coastal floods, risk perception, multiple regression analysis 


\section{INTRODUCTION}

\subsection{Background}

Flood hazards are world-wide considered as one of the most significant natural disasters in terms of human impact and economic losses. ${ }^{(1)}$ A specific type of flood hazards comprises coastal floods caused by storm surges. Storm surges imply a set-up of the sea level at coastal areas and are generally induced by strong winds and low atmospheric pressure. ${ }^{(2)}$ Examples of such storm surges are hurricanes, cyclones and typhoons. Recent disasters, such as hurricane Katrina in New Orleans (2005) and cyclone Sidr in Bangladesh (2007) have shown the catastrophic potential of coastal floods.

In Belgium, the most recent severe coastal flood occurred in 1953. Then, one of the largest storm surges of the last centuries struck the coastal areas surrounding the North Sea, leading to severe floods in Belgium, the Netherlands and United Kingdom. Because the time of the storm surge peak coincided with the time of spring-tide high water, the total water-level reached heights that, in many locations, exceeded those recorded ever before. The resulting disaster was enormous in terms of loss of life and damage to infrastructure. ${ }^{(3,4)}$ In the years ensuing, an important part of the Belgian sea walls was reinforced. ${ }^{(5)}$ These hard defence structures characterize the Belgian coast and nowadays constitute pleasant promenades for coast-dwellers. For several years, however, no new sea walls have been built. Instead, soft techniques such as beach feeding have been applied frequently. At present, nourishments are the main technical measures preventing the Belgian coast from a new disaster. ${ }^{(6)}$ In addition to these measures, numerous technological advances have been made in weather forecasting, risk mitigation procedures, emergency planning, etc. ${ }^{(7)}$

Both coastal defence investments and technological advances may have brought the public to a false sense of safety regarding flood hazards. Moreover, the rareness of events such as floods may allow social awareness of extreme and unsafe situations to fade. ${ }^{(8)}$ Due awareness of coastal flood risks remains however indispensable. In a Belgian context, two important developments underline this need. The first development is the global climate change. Climate models of the Intergovernmental Panel on Climate Change (IPCC) predict a global sea level rise of 0.3 to 0.6 meter during the $21^{\text {st }}$ century, leading to a higher vulnerability of coastal areas around the world. ${ }^{(9)}$ Focusing on the Belgian coast, Lebbe et al. ${ }^{(10)}$ have achieved similar findings. They state that, despite the natural and artificial defence structures, an increased vulnerability of the Belgian coastal plain is expected due to sea level rise. The second development is the growing economic importance of the Belgian coast. Approximately 0.4 million people ( $4 \%$ of the Belgian population) live in the flood prone area. During the summer period, this number increases by approximately 0.3 million resident tourists. The growing economic significance of the Belgian coast is a result of the flourishing beach tourism, the agriculture in the low-lying polder areas and a variety of fishing and harbour activities. ${ }^{(11)}$

As a consequence of the climate-change induced sea level rise and the continuing economic growth in the coastal area, parts of the Belgian coast are considered to be vulnerable to coastal floods, not only with regard to material vulnerability (tangible damage) but also human vulnerability (intangible damage). One of the major Flemish projects devoted to this issue is the Integrated Master Plan for Flanders Future Coastal Safety, led by the Agency for Maritime and Coastal Services. The main objective of this project (2007-2011) is to prepare the Belgian coast for storm surges, considering climate change impacts until 2050 . $^{(6)} \mathrm{A}$ similar project, CLIMAR, seeks for wide-ranging solutions regarding coastal defence structures on the Belgian coast. ${ }^{(12)}$ While these projects have extensively studied quantitative 
risk assessments, the public perception and opinion remain highly underexplored. Understanding people's risk perception and its determining factors is however crucial for improving risk communications and effective mitigation policies. ${ }^{(13,14)}$ The knowledge about risk perceptions of natural hazards may further provide important information about people's willingness to take precautionary measures, and the public support for governments' risk reduction policies. ${ }^{(15)}$ While risk perception studies have largely focused on inhabitants, far less attention has been given to the perception of tourist populations. Nonetheless, Burby and Wagner have underlined the vulnerability of tourists towards local hazards, because tourists are less independent and less familiar with local hazards and the resources that can be relied on to avoid risk. ${ }^{(16)}$

By means of a questionnaire survey, the current paper seeks to probe into the perception of inhabitants and resident tourists towards storm surges and flood risks along the Belgian coast. Using multiple regression analysis, insight is gained into how various personal, experiential and residence characteristics contribute to the level of risk perception. Attention is also paid to the correspondence of the perceived risk with the expert's risk assessment in high and low risk areas.

The remainder of this section gives a brief overview of literature related to the role of risk perception in flood risk management and to research regarding public perception versus expert's risk assessment. Based on available evidence in previous studies, research aims and hypotheses are formulated. Subsequently, research site selection, survey method and sample characteristics are described in Section 3. Section 4 presents the results of the multiple regression analysis. The paper ends with a discussion and outlines the avenues for further research in the field of flood risk perception.

\subsection{Risk Perception and Flood Risk Management}

The study of risk perception involves the examination of people's awareness, emotions and behaviour with regard to hazards. While originated in the nuclear debate of the $1960 \mathrm{~s}^{(17,18)}$, risk perception has become more and more prevalent in numerous other areas. One of these areas is flood risk management ${ }^{(19)}$ which comprises the comprehensive task of considering all natural and societal processes related to flood hazards. According to its conventional definition, risk is deemed a quantifiable variable and is analysed on the basis of probabilities and consequences. ${ }^{(20)}$ While risk analysis methods generally rely on aspects of objective risk measures, subjective risk measurement such as risk perception is currently being recognized as an essential aspect in the context of flood risk management. ${ }^{(21)}$ The knowledge of people's perception level allows researchers to identify qualitative risk characteristics (e.g. "voluntary", "immediate", "known to exposed", "known to science', "not controllable", etc.) and compare risks associated with different hazards. ${ }^{(22)}$ Furthermore, the knowledge of risk perception is promoted as prerequisite to achieve effective risk communication. ${ }^{(23)}$ Terpstra et al. ${ }^{(24)}$, for example, indicate that limited knowledge about risk perception of flood hazards may lead to difficulties in communicating these risks and, moreover, in unsatisfactory knowledge about risk reducing measures. Without thorough perception research, risk communication may suffer from limited understanding of the interests, concerns, fears, values, priorities, and preferences of individual citizens and public groups. ${ }^{(25)}$

\subsection{Expert versus Public in Risk Perception}

While experts have generally used statistical data to estimate and compare risks, the risk judgment of the public relies largely on qualitative factors, such as seriousness of the 
consequences, sense of control, and recency and (perceived) frequency of the hazard ${ }^{(26)}$. The discrepancy between the expert's risk assessment and the public's risk perception is often demonstrated in literature. ${ }^{(27)}$ Burningham et al. ${ }^{(28)}$, for example, reported difficulties in interpreting the meaning of a "one in a 50 year" flood: an older respondent answered she did not have to worry because she was already 75 years old. Another person in the study did not understand how a once in 50-year flood had occurred twice in five months. Some researchers, however, have refuted the statement that experts are more veridical in their risk assessments than members of the public. Rowe and Wright $^{(29)}$, for example, have identified methodological weaknesses in a number of empirical studies, such as poorly defined characteristics of the expert and the lay samples, and the absence of information to determine expert's reliability. Results of Siegrist and Gutscher ${ }^{(30)}$ confirm these weaknesses. Their study showed little to no evidence of differences in flood risk perception between the public and the experts.

\section{RESEARCH AIMS AND HYPOTHESES}

Past research about hazard perceptions has sought to identify and quantify the different factors that might predict people's attitude towards risk. ${ }^{(31)}$ In the context of flood risks, perception research has articulated the impact of personal experience with previous flood hazards and socio-demographic variables on perceived personal risk. ${ }^{\text {(e.g. } 15,32-34)}$ While most of these studies have examined the public perception of flood hazards in general, only few have explicitly focused on the perception of coastal flood risks. ${ }^{(35)}$ Furthermore, the ways in which residence characteristics (e.g. residing on ground floor) may affect flood risk perception has remained understudied in the context of flood risks. ${ }^{(36)}$ Finally, from Section 1.3 , it appears that there is also still no consensus with respect to the "expert versus public" issue.

This study explicitly addresses these issues in a case study on the Belgian coast. Based on previous evidence from the literature, which is reviewed below, five hypotheses are formulated. The first three hypotheses concern the effect of expert's risk assessment (location), socio-demographic factors and residence characteristics on risk perception. Hypothesis 4 and 5 consider the mediating effect of hazard experience variables and the moderating effect of residing permanently on the Belgian coast for the relation between location and risk perception, respectively.

\subsection{Expert's Risk Assessment (Location)}

In this study, the perception of inhabitants and resident tourists of flood risks is measured in three coastal municipalities on the Belgian coast: Ostend, Knokke-Heist and De Panne (with $69.000,34.000$ and 10.000 inhabitants, respectively). Figure 1 depicts the location of the studied municipalities, together with a summary of the present defence structures. The municipalities were selected because they exhibit diverse characteristics in terms of (i) the scientifically estimated flood risk, (ii) the presence of coastal defence structures and (iii) the impact of the storm surge of 1953. These characteristics will be discussed below. 


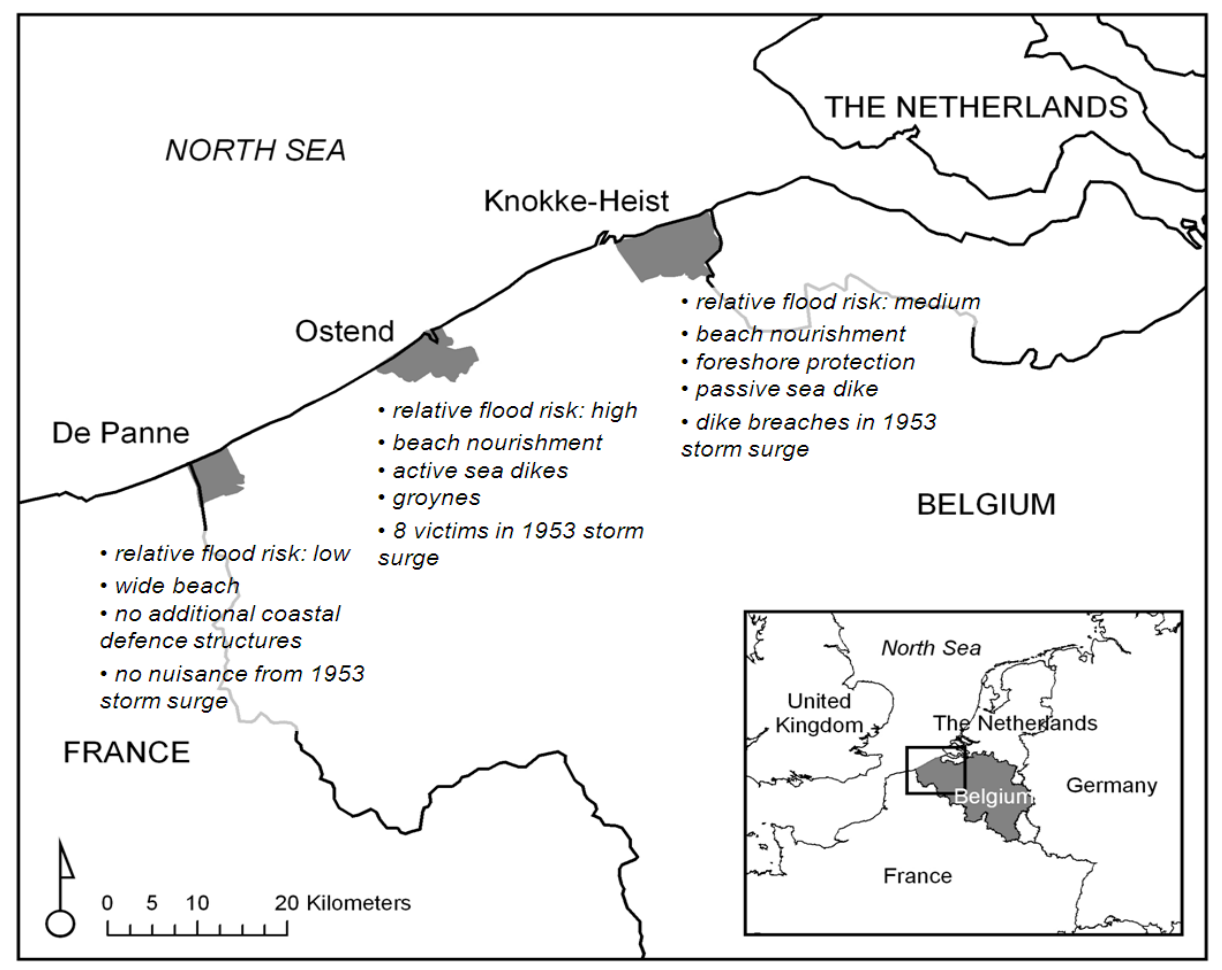

Figure 1 Location of the study area with a summary of the selection factors

In recent years, experts from Flanders Hydraulic Research (Belgium) have combined various hydraulic models with socio-economic data to produce damage and risk maps for both river and coastal flood scenarios. ${ }^{(37)}$ According to these risk assessments, Ostend is expected to have higher flood risks than De Panne and Knokke-Heist. Unlike the other municipalities, several parts of Ostend are located at an elevation below high tide sea level. The municipality of De Panne on the contrary is considered to have one of the safest beaches regarding flood risks. A combination of a wide beach -450 meters at low tide - and a mean elevation above high tide sea level results in a relatively low coastal flood risk. According to estimates, the actual flood risk in Knokke-Heist is somewhat higher than in De Panne but considerably lower than in Ostend.

The examined municipalities further differ in the presence of coastal defence structures. In Ostend, the most important defence structures are beach nourishment (artificial raising of the beach), an active sea dike and groynes. The town of Knokke-Heist is protected by beach nourishment, foreshore protection and a passive sea dike. In De Panne, no additional defence structures are applied. The wide beach makes extra defence efforts superfluous.

Finally, the 1953 storm surge had a quite different impact on the examined municipalities. In the city centre of Ostend, average water depths amounted to $93 \mathrm{~cm}$. The inundation was primarily caused by the fishing port's dikes which were not high enough to compete against the water level. In total, eight people were killed in Ostend. In Knokke-Heist, coastal dikes were damaged and parts of the town flooded, though much less extensive than in Ostend. The municipality of De Panne experienced practically no nuisance from the severe storm. ${ }^{(38)}$

Given the above characteristics regarding the expert's risk assessment, the coastal defence structures and the storm surge experience, a reasonable distinction can be made between a high risk area (Ostend) and a low risk area (Knokke-Heist and De Panne), leading to the first hypothesis: 
H1: It is expected that respondents from Ostend (high expert's risk assessment) will exhibit higher levels of perceived risk than those from Knokke-Heist and De Panne (low expert's risk assessment).

\subsection{Socio-Demographic Factors}

Individual socio-demographic characteristics can play an important role in shaping risk perception of natural hazards. ${ }^{(31,39)}$ For example, risk appears to be a gendered phenomenon: woman are more risk averse than men. ${ }^{(40)}$ Jonkman and Vrijling ${ }^{(2)}$ found that on average $70 \%$ of the casualties in flood hazards are male. They attribute this gender discrepancy to the high involvement of men in driving, the high proportion of men in the emergency and supporting services, and men's risk-taking behaviour. These findings may suggest that men have on average a lower risk perception than women. Also often associated with risk perception are the factors age and household composition. Age has been found to be positively correlated with risk perception of a number of natural hazards. ${ }^{(41,42)}$ Household composition is generally defined by the presence or number of children in het household. The literature is equivocal about the influence of this factor on risk perception. Houts et al. ${ }^{(43)}$, for example, have concluded that the presence of children is a primary indicator of a household's perceived susceptibility to a nuclear threat. Similar outcomes were reported regarding volcano risk perception $^{(44)}$ and evacuation response ${ }^{(45)}$. In the domains of earthquake ${ }^{(46)}$ and hurricane risks $^{(39)}$, however, presence of children did not have significant effects on perceived risk. Further, education can also be associated with risk perception. In the context of technological hazards, Savage ${ }^{(47)}$ found that lower educated people show higher levels of risk perception. Finally, home ownership has also been related to perceived risks. Past research on flood hazards ${ }^{(28,41)}$ suggests that owning a property results in higher levels of perceived risk than renting a residence. Finally, it has been argued that staying permanently on a hazardous place may amplify risk perception. ${ }^{(42)}$

The above findings provide a rationale for Hypothesis 2. Because of literature disagreement, the effects of presence of children are not hypothesized.

H2: Coastal flood risk perception is expected to be positively related with age, female gender, lower education, home ownership, and permanent residence.

\subsection{Residence Characteristics}

The characteristics of a person's residence can be determinant towards flood damage. It has been reasoned that people having a cellar or residing on the ground floor, are more vulnerable to flooding. Kreibich et al. ${ }^{(36)}$, for example, formulated a set of precautionary measures in which an elevated configuration and fortification of cellar and ground floor are advised for buildings in flood prone areas. Siegrist ${ }^{(48)}$ on the other hand, mentions that 20 to $36 \%$ of the people store valuable content in their cellars. In Belgium, cellars often contain the electricity closet and the heating system. The presence of water in the vicinity of these systems may result in power failure and damage to household appliances, computers, televisions and other electronic devices in the house or apartment building. Most cellars on the Belgian coast are situated below high tide sea level.

An additional residence characteristic deals with the visibility of the hazard from the residence location. This characteristic is closely related to hazard proximity. In past research, correlations between hazard proximity and perceived risk have been found for technical 
hazards such as chemical installations ${ }^{(49)}$ and for natural hazards such as earthquakes ${ }^{(50)}$, hurricanes ${ }^{(51)}$ and floods ${ }^{(52)}$. It seems that people who are farther away from hazard sources, exhibit lower levels of perceived risk. ${ }^{(42)}$ However, to date there is little consensus about about the effects of hazard visibility on risk perception. While some (e.g. Burningham et al. ${ }^{(28)}$ ) have argued positive relations between visibility and perception of flood hazards, others (e.g. Colten and Sumpter ${ }^{(8)}$ ) have argued that visible cues of rare hazard sources - such as floods - might cause a false sense of safety, resulting in lower levels of risk perception. Apart from this literature disagreement, we will go with the majority of research findings and hypothesize a positive relation between sea view and risk perception.

These arguments provide a rationale for Hypothesis 3:

H3: Residing on the ground floor, or residing in a house with a cellar or sea view will be related to higher levels of coastal flood risk perception.

\subsection{Location and Hazard Experience}

Many researchers have stressed the importance of previous hazard experiences in people's judgments about risk. ${ }^{(36,41,53)}$ Distinction is often made between direct personal experience and vicarious experience. Direct personal experience can be defined by the recency and frequency of casualties and damage experienced by the respondent. ${ }^{(42)}$ Vicarious experience refers to social communication, i.e. hearing or reading about hazard impacts affecting friends, relatives or neighbours. Because attitudes based on direct experiences are more accessible in memory, direct personal experience has a greater potential to influence perceived personal risk. ${ }^{(54)}$ Past research supports this thesis. In a multi-hazard environment, Lindell and Hwang $^{(42)}$ found that people who have previously been exposed to a hazard were far more aware than people without hazard experience. Hazard experience may also be determined by location. People staying on locations exposed to higher risk values will have a greater chance of experiencing risk-related events, e.g. people staying on the coast have a greater chance of experiencing a hazardous storm surge than people living inland. This argumentation invokes a mediating relation between location and perceived personal risk via hazard experience.

Two types of hazards are considered in this study: floods and storm surges. Storm surges are defined as a set-up of the sea level at coastal areas, sometimes resulting in over-topping of sea water on dikes. ${ }^{(55)}$ In case of structural failing such as dike breaching, a storm surge can result in coastal flooding (cf. 1953 storm surge). Although the focus of this study is on the perception of coastal flood risks, experience with flood types occurring inland (e.g. river floods) is also taken into account because these might influence the perception of hazards in general. ${ }^{(56)}$ This is particularly relevant in our case study given that the survey also considers coastal tourists, who may have experience with flood types other than coastal floods or coastal storm surges.

Hypothesis 4 is stated as follows:

H4: The effect of location on perceived personal risk is expected to be mediated by direct personal experience with storm surges and/or (coastal) floods.

\subsection{Location and Permanent Residence}

The factors location and permanent residence have been discussed before (see Hypothesis 1 and 2 respectively). However, it can be argued that both factors might interact. Assuming that 
residents usually have more belongings that can be damaged by a flood compared to (visiting) tourists, location will have a differential impact on risk perception for both categories of respondent type. To be more precise, residents living permanently in a high-risk place (Ostend) exhibit higher risk perception compared to residents living permanently in a low-risk place (Knokke-Heist and De Panne). Moreover, it is expected that location will not affect tourists' risk perception. This reasoning results in the fifth Hypothesis:

H5: Location will impact risk perception for residents but not for tourists.

\section{METHODOLOGY}

\subsection{Survey Method}

The survey method consists of a paper questionnaire, containing scaled items regarding storm surges and coastal flood risks. Based on questionnaires previously developed in the context of flood risk perception ${ }^{(24)}$, five items were selected and - if necessary - adapted for the present research (Table I). All items were measured on a 5 point-scale ranging from no agreement at all (score: 1) to full agreement (score: 5), with a neutral opinion in between (score: 3). Cronbach's alpha of the five risk perception items is .80, indicating an adequate internal consistency. Principal factor analysis with varimax rotation was used to obtain just one component having an eigenvalue above 1 (explained variance 55.4\%). Based on the factor loadings on this component, weighted factor scores are assigned to all observations. The resulted risk perception score follows a normal distribution $N(0,1)$ and ranges from -2.39 to 2.19. Higher values indicate stronger levels of risk perception and vice versa.

Table I Perception of flood risk: items

\begin{tabular}{ll}
\hline 1 & I'm worried about the danger of a storm surge on the Belgian coast \\
2 & A storm surge can have fatal consequences for the coastal area and its inhabitants \\
3 & I experience staying on the Belgian coast as a threat to my safety \\
4 & I expect great chances of storm surges causing floods in the coastal area \\
5 & When I think of floods, I feel concerned
\end{tabular}

Socio-demographic characteristics and information regarding hazard experience were assessed as follows. Age was measured as a continuous scale in years, gender was obtained as dichotomy (female $=1$, male $=0$ ). Home ownership, residing permanently on the Belgian coast, presence of children at home and direct personal experience with past storm surges and floods were all measured as dichotomy (yes $=1$, no $=0$ ), as well as education ("high education" (i.e. high school or university degree) $=1$; "low education" (i.e. primary or secondary school degree) $=0$ ). Additionally, three residence characteristics were obtained: (i) having a cellar, (ii) living on the ground floor and (iii) staying in a residence with sea view (all three were measured as dichotomy: yes $=1$, no $=0$ ). Finally, location was coded as follows: Ostend (high expert risk assessment) $=0$; Knokke-Heist/De Panne (low expert's risk assessment $)=1$.

Given the current aim of evaluating risk perception at two locations along the Belgian coast, the survey is organized as a stratified sampling with proportional allocation. The size of the subsamples in each stratum (municipality) was chosen in proportion to the size of the stratum. The number of permanent inhabitants is used as size indicator for each stratum, 
leading to a partition of $60 \%$ for Ostend compared to $40 \%$ for Knokke-Heist and De Panne. Two different distribution methods were used. The first method involved distribution of questionnaires via systematic sampling in postboxes (5/6 of all questionnaires). In order to reach sufficient respondents having sea view, a number of streets were randomly selected in the vicinity of the shoreline. The second method consisted in personally handing over the questionnaires to inhabitants and residents in the streets of the three municipalities, thereby providing a brief word of explanation. It was hoped that this personal hand-over would result in a higher response rate.

\subsection{Sample Characteristics}

Overall, 619 respondents (20.6\%) answered the questionnaire. Table II lists the response rates per location (Ostend; Knokke-Heist and De Panne) for both personal hand-overs and postboxes. As was hoped, the personal hand-over method resulted in a considerably larger response rate than the postbox method (35.4\% against $17.7 \%$ respectively). In general, response rates were somewhat better in Ostend than in Knokke-Heist and De Panne $(22.5 \%$ to $17.8 \%$ respectively).

Table II Response numbers in each municipality according to distribution method (personal hand-over/ via postboxes)

\begin{tabular}{llllllll}
\hline & & \multicolumn{2}{l}{ Personal hand-over } & Postboxes & \multicolumn{2}{l}{ Total } \\
\cline { 3 - 8 } & & Number & $\%$ & Number & $\%$ & Number & $\%$ \\
\hline Location & Ostend & 96 & 32.0 & 309 & 20.6 & 405 & 22.5 \\
& Knokke-Heist + & 81 & 40.5 & 133 & 13.3 & 214 & 17.8 \\
\cline { 3 - 7 } Total & De Panne & 177 & 35.4 & 442 & 17.7 & 619 & 20.6 \\
\hline
\end{tabular}

Table III displays the overall frequencies of the personal characteristics. Respondent's age ranged from 17 to 88 years $($ mean $=58.3$, s.d. $=14.3)$. The majority of the sample $(66 \%)$ were male, which can be attributed to the fact that the questionnaire was addressed to the head of the family. The ratio between owners and non-owners of residences is about three to one. Approximately $70 \%$ of the sample resides permanently on the Belgian coast. These values closely mirror the actual situation, as measured by the research and consultancy office of West-Flanders (WES). ${ }^{(57)}$ The ratio between the number of people with a low educational level (i.e. degree of primary or secondary school) and a high educational level (i.e. high school or university degree) is about fifty-fifty. Roughly one fourth of the respondents has one or more children living at home.

The question as to whether or not the respondents had experience with previous storm surges resulted in remarkable outcomes. While half of the respondents reports to have witnessed a storm surge on the Belgian coast, less than one out of four participants answered affirmative to the question "Have you ever experienced a flood in the past?" The smaller percentage of people having experienced floods compared to storm surge experience results from the fact that not every storm surge causes a flood. Noteworthy is that the storm surge of 1953 was mentioned quite often in an open question ("Can you indicate the year of the most severe storm surge you have experienced to date?"). In Ostend, $34 \%$ of the respondents with storm surge experience refer to the one of 1953 against a minority ( $c$. $10 \%)$ in the two other municipalities.

Three additional variables were questioned regarding the respondent's present residence on the coast: (i) having sea view or not, (ii) living on the ground floor or not and (iii) having a 
cellar or not. Table III indicates that roughly one third of the respondents has sea view, one third lives on the ground floor and one third lacks a cellar.

Table III Sample statistics: frequency in numbers and percentage per variable

\begin{tabular}{|c|c|c|c|c|c|c|c|c|}
\hline Variable & Number & Percentage & Variable & Number & Percentage & Variable & Number & Percentage \\
\hline \multicolumn{3}{|l|}{ Age } & \multicolumn{3}{|c|}{ Education } & \multicolumn{3}{|l|}{ Sea view } \\
\hline $16-30$ & 27 & 4.4 & High & 314 & 50.7 & Yes & 220 & 35.5 \\
\hline $31-45$ & 82 & 13.2 & Low & 299 & 48.3 & No & 385 & 62.2 \\
\hline $46-60$ & 219 & 35.4 & Missing & 6 & 1.0 & Missing & 14 & 2.3 \\
\hline $61-75$ & 221 & 35.7 & & & & & & \\
\hline $76-90$ & 68 & 11.0 & \multicolumn{3}{|c|}{ Children living at home } & \multicolumn{3}{|c|}{ Ground floor } \\
\hline \multirow[t]{2}{*}{ Missing } & 2 & 0.3 & Yes & 167 & 27.0 & Yes & 185 & 29.9 \\
\hline & & & No & 448 & 72.4 & No & 418 & 67.5 \\
\hline \multicolumn{3}{|l|}{ Gender } & Missing & 4 & 0.6 & Missing & 16 & 2.6 \\
\hline Male & 409 & 66.1 & & & & & & \\
\hline Female & 209 & 33.8 & \multicolumn{3}{|c|}{ Storm surge experience } & \multicolumn{3}{|l|}{ Cellar } \\
\hline \multirow[t]{2}{*}{ Missing } & 1 & 0.2 & Yes & 303 & 48.9 & Yes & 386 & 62.4 \\
\hline & & & No & 313 & 50.6 & No & 214 & 34.6 \\
\hline \multicolumn{3}{|c|}{ Home ownership } & Missing & 3 & 0.5 & Missing & 19 & 3.1 \\
\hline Owner & 474 & 76.6 & & & & & & \\
\hline Tenant & 142 & 22.9 & \multicolumn{3}{|c|}{ Flood experience } & & & \\
\hline \multirow[t]{2}{*}{ Missing } & 3 & 0.5 & Yes & 139 & 22.5 & & & \\
\hline & & & No & 477 & 77.1 & & & \\
\hline \multicolumn{3}{|c|}{ Permanent residence } & Missing & 3 & 0.5 & & & \\
\hline Yes & 438 & 70.8 & & & & & & \\
\hline No & 181 & 29.2 & & & & & & \\
\hline Missing & 0 & 0.0 & & & & & & \\
\hline
\end{tabular}

\section{RESULTS}

In this study, two analyses are conducted. First, a correlation analysis is performed to check for multicollinearity among predictor variables. A multiple regression analysis is consequently used to explore the predictive values of location, personal and residential characteristics, as well as hazard experience for perceived levels of coastal flood risks.

\subsection{Correlation Analysis}

Table IV depicts the correlations between all variables: personal characteristics (6), hazard experience (2), residential characteristics (3) and location (1).

Among the significant relevant correlations are those concerning the variables permanent residence, storm surge experience and location. A high positive correlation between permanent residence and storm surge experience shows that inhabitants more frequently observe storm surges than tourists. As for location, significant negative correlations were found with the variables permanent residence and storm surge experience, indicating that more respondents reside permanently in Ostend than in the other municipalities. The negative correlation between location and storm surge experience illustrates a higher storm surge experience in Ostend.

Most importantly, the analysis showed no correlations higher than 0.60 which is a strong indication for the absence of multicollinearity among the predictors. 
Table IV Correlations between variables

\begin{tabular}{|c|c|c|c|c|c|c|c|c|c|c|c|c|c|c|c|}
\hline & & Mean & $N$ & 1 & 2 & 3 & 4 & 5 & 6 & 7 & 8 & 9 & 10 & 11 & 12 \\
\hline 1 & Age & $\begin{array}{c}58.30 \\
\text { (s.d. } 14.263)\end{array}$ & 617 & - & & & & & & & & & & & \\
\hline 2 & Gender & .34 & 618 & $-.174 * *$ & - & & & & & & & & & & \\
\hline 3 & Home ownership & .77 & 616 & $.165 * *$ & -.008 & - & & & & & & & & & \\
\hline 4 & Permanent residence & .71 & 619 & .068 & .044 & $.205^{* *}$ & - & & & & & & & & \\
\hline 5 & Education & .51 & 613 & -.043 & -.038 & .073 & $-.128 * *$ & - & & & & & & & \\
\hline 6 & Children living at home & .27 & 616 & $-.385 * *$ & .066 & .031 & -.063 & .073 & - & & & & & & \\
\hline 7 & Storm surge experience & .49 & 616 & $.204 * *$ & .001 & $.106 * *$ & $.339 * *$ & -.041 & $-.111 * *$ & - & & & & & \\
\hline 8 & Flood experience & .23 & 616 & $.081^{*}$ & -.014 & .009 & .031 & .016 & .015 & .051 & - & & & & \\
\hline 9 & Sea view & .36 & 605 & .068 & -.021 & -.025 & $-.317 * *$ & $.163^{* *}$ & $-.145^{* *}$ & $-.081^{*}$ & -.064 & - & & & \\
\hline 10 & Ground floor & .31 & 603 & -.056 & .038 & $.207^{* *}$ & $.281 * *$ & -.055 & $.189^{* *}$ & $.093^{*}$ & .046 & $-.368 * *$ & - & & \\
\hline 11 & Cellar & .64 & 600 & .018 & .010 & -.021 & $-.100 *$ & $.103 *$ & -.064 & -.053 & $.097 *$ & $.181 * *$ & $-.134 * *$ & - & \\
\hline 12 & Location & .35 & 619 & .039 & $-.087 *$ & -.025 & $-.466 * *$ & $.198 * *$ & -.064 & $-.303^{* *}$ & .010 & $.301 * *$ & $-.175^{* *}$ & $.184 * *$ & - \\
\hline
\end{tabular}




\subsection{Regression Analysis}

We used multiple regression analyses to test the five hypotheses. The following hierarchical testing procedure was used. Model 1 tested for the partial effects of location (i.e., Hypothesis 1), socio-demographic characteristics (i.e., Hypothesis 2), and residence characteristics (i.e, Hypothesis 3) on risk perception. Model 2 tested for multiple mediation between location and risk perception via hazard experience variables (i.e., Hypothesis 4). Model 3 tested for the moderating effect of permanently residing on the relationship between location and risk perception (i.e., Hypothesis 5).

Table $\mathrm{V}$ depicts the results of the different models. Model 1 performance was relatively low with about 9.9 percent of variation in risk perception explained by the predictor set. The hypothesis stating that location is associated with perceived risk was confirmed. Since Ostend functioned as the reference category, the negative B-value indicated lower perception levels in Knokke-Heist and De Panne compared to Ostend. As indicated by the squared part correlations, two out of six socio-demographic characteristics, namely age and gender, were also found to contribute uniquely to the prediction of risk perception thereby confirming the second hypothesis. As denoted by the positive B-value, older respondents tend to have a higher perceived level of flood risk. Gender was also linked to a positive B-value, indicating higher levels of risk perception for women than for men. The prediction of risk perception from the three residence characteristics proved non-significant, thereby disconfirming the third hypothesis.

A marginal improvement was found for the percentage of explained variance in risk perception after hazard experience variables were added to Model $1\left(\Delta \mathrm{R}^{2}\right.$ Model $2=.008, \mathrm{p}=$ .08). Model 2 functioned as a multiple mediation test for the effect of location on risk perception via hazard experience variables. The significance of the reduction in B-value for location between Models 1 and 2 is equivalent to the significance of the total indirect or multiple mediating effect through hazard experience variables (Hypothesis 4). A bootstrapping procedure was used to investigate the statistical significance of the total and partial indirect effects. ${ }^{(58)}$ Bootstrapping is an alternative method to the widely used Sobel test for testing mediation, as advocated by Baron and Kenny. ${ }^{(59)}$ Bootstrapping is a nonparametric re-sampling procedure in which indirect effects are repeatedly estimated (e.g., 5000 times) to create a non-normal distribution of the indirect effect estimates. This distribution is then used to construct asymmetric confidence intervals (CIs) around the point estimates (PE's) of the indirect effects. We reported on the $95 \%$ bias-corrected and accelerated $(\mathrm{BCa}) \mathrm{CIs}$ which signaled significance of indirect effects when zero was not contained in the intervals. The $P E$ of the total indirect effect was not significantly different from zero $(P E=-0.01, S E=0.03)$ with $95 \%$ confidence (BCa 95\% CI of -0.06 to 0.04). Similar results were obtained for the partial indirect effects related to storm surge (BCa 95\% CI of -0.06 to 0.03 ) and flood experiences (BCa 95\% CI of -0.01 to 0.03 ), respectively. In conclusion, hazard experience variables did not mediate the effect of location on risk perception. Instead, flood (but not storm surge) experience independently predicted risk perception.

A slight improvement was found for the percentage of explained variance in risk perception after the moderating effect of permanently residing on the relationship between location and risk perception was added to Model $2\left(\Delta \mathrm{R}^{2}\right.$ Model $\left.3=.006, \mathrm{p}=.06\right)$. Following the procedure indicated by Aiken and West ${ }^{(60)}$, an interaction term was calculated between location and permanently residing. Tourists functioned as the reference category. For tourists, the simple effect for location indicated lower perception levels in Knokke-Heist and De Panne ( $\mathrm{M}_{\text {adjusted }}$ $=-0.21)$ compared to Ostend $\left(\mathrm{M}_{\text {adjusted }}=0.26\right)$. A rerun of Model 3 with the dummy coding 
for permanently residing reversed indicated equal perception levels $(\mathrm{B}=-.08, p=.54)$ for inhabitants in Knokke-Heist and De Panne $\left(\mathrm{M}_{\text {adjusted }}=-0.03\right)$ compared to Ostend $\left(\mathrm{M}_{\text {adjusted }}=\right.$ 0.05). The difference in the simple effects of location on risk perception between tourists and inhabitants indicated a marginal significant interaction effect (identical to $\Delta \mathrm{R}^{2}$ Model 3 ) of permanently residing and location in predicting risk perception.

In sum, risk perception is higher when respondents are older, female, have flood experience, and are tourists visiting Ostend. 
Table V Regression analysis

\begin{tabular}{|c|c|c|c|c|c|c|c|}
\hline & & $B$ & $S E B$ & Beta & $\mathrm{t}$ & $p$ & $\begin{array}{l}\text { squared part } \\
\text { correlation }(\%)\end{array}$ \\
\hline \multicolumn{8}{|l|}{ Model 1} \\
\hline & Location & -.21 & .10 & -.10 & -2.08 & .04 & 0.7 \\
\hline & Age & .02 & .00 & .21 & 4.67 & .00 & 3.4 \\
\hline & Gender & .32 & .09 & .15 & 3.73 & .00 & 2.2 \\
\hline & Home ownership & .11 & .10 & .05 & 1.10 & .27 & 0.2 \\
\hline & Permanent residence & .02 & .11 & .01 & 0.20 & .84 & 0.0 \\
\hline & Education & -.09 & .08 & -.04 & -1.05 & .30 & 0.4 \\
\hline & Children living at home & -.15 & .10 & -.07 & -1.53 & .13 & 0.4 \\
\hline & Sea view & -.12 & .10 & -.06 & -1.23 & .22 & 0.2 \\
\hline & Ground floor & .06 & .10 & .03 & 0.57 & .57 & 0.0 \\
\hline & Cellar & .08 & .09 & .04 & 0.90 & .37 & 0.1 \\
\hline \multicolumn{8}{|l|}{ Model 2} \\
\hline & Location & -.20 & .10 & -.09 & -1.93 & .05 & 0.6 \\
\hline & Age & .01 & .00 & .19 & 4.26 & .00 & 2.8 \\
\hline & Gender & .32 & .09 & .15 & 3.70 & .00 & 2.1 \\
\hline & Home ownership & .12 & .10 & .05 & 1.12 & .26 & 0.2 \\
\hline & Permanent residence & .01 & .11 & .00 & 0.08 & .94 & 0.0 \\
\hline & Education & -.09 & .08 & -.05 & -1.12 & .26 & 0.2 \\
\hline & Children living at home & -.16 & .10 & -.07 & -1.59 & .11 & 0.4 \\
\hline & Sea view & -.10 & .10 & -.05 & -1.08 & .28 & 0.2 \\
\hline & Ground floor & .05 & .10 & .02 & 0.51 & .61 & 0.0 \\
\hline & Cellar & .06 & .09 & .03 & 0.67 & .50 & 0.1 \\
\hline & Storm surge experience & .06 & .09 & .03 & 0.64 & .52 & 0.1 \\
\hline & Flood experience & .21 & .10 & .09 & 2.14 & .03 & 0.7 \\
\hline \multicolumn{8}{|l|}{ Model 3} \\
\hline & Location & -.47 & .18 & -.22 & -2.66 & .01 & 1.1 \\
\hline & Age & .01 & .00 & .20 & 4.33 & .00 & 2.9 \\
\hline & Gender & .31 & .09 & .15 & 3.62 & .00 & 2.0 \\
\hline & Home ownership & .12 & .10 & .05 & 1.15 & .25 & 0.2 \\
\hline & Permanent residence & -.22 & .16 & -.10 & -1.32 & .19 & 0.3 \\
\hline & Education & -.09 & .08 & -.04 & -1.03 & .30 & 0.2 \\
\hline & Children living at home & -.16 & .10 & -.07 & -1.58 & .12 & 0.4 \\
\hline & Sea view & -.11 & .10 & -.05 & -1.12 & .26 & 0.2 \\
\hline & Ground floor & .05 & .10 & .02 & 0.54 & .59 & 0.0 \\
\hline & Cellar & .06 & .09 & .03 & 0.68 & .50 & 0.1 \\
\hline & Storm surge experience & .06 & .09 & .03 & 0.68 & .50 & 0.1 \\
\hline & Flood experience & .21 & .10 & .09 & 2.15 & .03 & 0.7 \\
\hline & Location X Permanent residence & .39 & .21 & .14 & 1.88 & .06 & 0.5 \\
\hline
\end{tabular}

\section{DISCUSSION}

In this paper, we have examined the public perception of coastal flood risks on the Belgian coast. To this end, a set of variables was considered in relation to risk perception, namely location, hazard experiences, socio-demographic characteristics and residence characteristics. Through hierarchical testing of three regression models, five hypotheses were tested.

In Model 1, partial effects of location, socio-demographic characteristics and residence characteristics were investigated on risk perception. Consistent with Hypothesis 1, we found 
that levels of risk perception varied significantly across location. In the city of Ostend, higher levels of risk perception were measured than in Knokke-Heist and De Panne. The higher level of risk perception in Ostend corresponds to the expert's risk estimates. Our findings suggest that the differences between the expert and the public are rather myth than reality. However, this finding should be interpreted with caution, given that only two locations were considered in our study. Additional empirical research will be necessary to confirm these findings in the context of coastal flood risks.

Consistent with Hypothesis 2, age was positively correlated with perception of coastal flood risks. Older respondents scored on average higher on the different perception characteristics than younger people. This is in line with Grothmann et al. ${ }^{(41)}$, who have found similar effects for people in flood prone areas. Also consistent with Hypothesis 2, female gender was positively correlated with risk perception. Women's risk averse behaviour tends to have repercussions on the perception of coastal flood risks as well. This is in line with perception research on natural hazards in general, and on flood hazards in particular. ${ }^{(42)}$ Interestingly, home ownership was not related to risk perception. Resident owners and tenants exhibited similar levels of perceived flood risks, which is at variance with earlier research. ${ }^{(28,41)}$ This different outcome may be due to alternative methods of measuring risk perception. While Burningham et al. ${ }^{(28)}$ focused on risk awareness, Grothmann et al. ${ }^{(41)}$ measured perceived ability to take protective actions regarding flood risks. Finally, effects of residing permanently on the coast were tested in this study. Based on previous research ${ }^{(28,42)}$, it was hypothesized that inhabitants would have higher levels of flood risk perception than resident tourists. Regression analysis, however, revealed no significant effect of permanent residence on perceived risk levels.

Apart from location and socio-demographic characteristics, three additional factors regarding residence setting were tested in our study, namely visibility of the sea, having a cellar and living on the ground floor. Against the expectations, none of these variables showed a significant effect on risk perception, thereby disconfirming the third hypothesis. A possible explanation for the outcomes of "cellar" and "ground floor" might be that the items which measured risk perception did not explicitly focus on property value and material belongings. As such, personal damage to property in cellars or ground floors were possibly not accurately measured. We could further not elucidate the discrepancy present in literature regarding hazard visibility. The visibility of the sea might have an effect on risk perception, but we were not able to measure it.

Model 2 tested for multiple mediation between location and risk perception via two hazard experience variables: storm surge experience and flood experience (Hypothesis 4). A mediation effect was not found, although a partial effect on risk perception was observed for flood experience. Apparently, the effect of location on risk perception is determined by other (psychological) processes, which were not measured in this study. One process, for example, might be that public works to coastal defences - such as beach nourishment - were mainly executed in Ostend during the last years. The visual impact of these public works may cause higher levels of perceived risk. This might be particularly the case for tourists visiting the Belgian coast occasionally. These could be elements for further research.

The rationale for Model 3 (Hypothesis 5) was that residents of Ostend will exhibit a higher risk perception because they are at higher risk. For resident tourists, this effect should be absent. However, the opposite was found in the analysis. Instead of inhabitants, resident tourists in Ostend appear to have a higher risk perception compared to other municipalities. Possible explanations for this finding may be a certain habituation of inhabitants towards the risks of storm surges or risk priming effects in case of tourists. More research is necessary to clarify this issue. 
Some methodological limitations of the current study must be acknowledged. First, bias can arise from non-response. People who decide not to fill in the questionnaire may have informative reasons not to do so. Second, the survey was restricted to only three municipalities on the Belgian coast. General conclusions for the entire Belgian coast - or other coastal areas - are therefore to be drawn with circumspection. Third, the regression model accounts for a relatively low percentage of the variance, suggesting the presence of noise or variation when examining risk perception. ${ }^{(39)}$ Through the very large sample in the survey, significant associations could nevertheless be detected. This issue has also been reported by Lindell and Perry ${ }^{(50)}$, who examined demographic characteristics and seismic hazard adjustments. They argued that demographic variables have small correlations that are statistically significant only in very large samples. To a certain extent, our findings seem to support this suggestion.

Despite its limitations, the present study has provided increased insights into the public perceptions of coastal flood risks. Our findings suggest that older people, women and people with flood experience have higher perceived levels of coastal flood risks. Regarding location, consistency was found between expert's risk estimates and public risk perception, although the effect of location on risk perception is nuanced through the moderating effect of respondent type. Tourists visiting Ostend show higher levels of risk perception than tourists visiting the other municipalities. Future work may examine the different responses to flood hazards between inhabitants and resident tourists in further detail. Consequently, governmental risk awareness programs should be content specific, and tuned upon the specific target group to be affected. Insights in the psychological processes of different target groups influencing risk perception is therefore of vital importance. For example, our study revealed that the effect of location is not mediated by hazard experience, but tends to be determined by other (psychological) processes. We believe these and future findings may advance the communication between experts and citizens regarding coastal flood risks.

\section{ACKNOWLEDGEMENTS}

Financial support for this work was provided by Research Foundation - Flanders. The authors would like to thank the anonymous referees for their valuable comments and suggestions on earlier drafts of this paper.

\section{REFERENCES}

1. Jonkman SN. Global perspectives on loss of human life caused by floods. Natural Hazards, 2005; 34(2):151-175.

2. Jonkman SN and Vrijling JK. Loss of Life due to Floods. Journal of Flood Risk Management, 2008; 1(1):43-56.

3. Gerritsen H. What happened in 1953? - The big flood in the Netherlands in retrospect. Philosophical Transactions of the Royal Society a-Mathematical Physical and Engineering Sciences, 2005; 363(1831):1271-1291.

4. Baxter PJ. The east coast Big Flood, 31 January-1 February 1953: a summary of the human disaster. Philosophical Transactions of the Royal Society a-Mathematical Physical and Engineering Sciences, 2005; 363(1831):1293-1312.

5. Charlier RH and Demeyer CP. Tourism and the Coastal Zone - the Case of Belgium. Ocean \& Coastal Management, 1992; 18(2-4):231-240. 
6. Mertens T, Trouw K, Bleukens K, De Nocker L, Couderé K, Sauwer C, De Smedt P, Lewis C and Verwaest T. SAFECoast: Integrated Master Plan for Flanders Future Coastal Safety. Belgium: Coastal Division of the Flemish Community, 2008.

7. McRobie A, Spencer $\mathrm{T}$ and Gerritsen H. The big flood: North Sea storm surge. Philosophical Transactions of the Royal Society a-Mathematical Physical and Engineering Sciences, 2005; 363(1831):1263-1270.

8. Colten CE and Sumpter AR. Social memory and resilience in New Orleans. Natural Hazards, 2009; 48(3):355-364.

9. Intergovernmental Panel on Climate Change (IPCC). Climate Change 2007: impacts, adaptation and vulnerability. In: Parry ML, Canziani OF, Palutikof JP, Linden PJvd and Hanson CE, editor. Contribution Group II to the fourth assessment report of the intergovernmental panel on climate change. Cambridge, UK: Cambridge University Press; 2007,

10. Lebbe L, Van Meir $\mathrm{N}$ and Viaene P. Potential implications of sea-level rise for Belgium. Journal of Coastal Research, 2008; 24(2):358-366.

11. Allaert G. De Belgische kust: tekenen van een recente revival? Ghent University, Belgium. 1996.

12. Van der Biest K. Evaluation of Climate Change Impacts and Adaptation Responses for Marine Activities (CLIMAR). Management Unit of the North Sea Mathematical Models (MUMM), Intermediary Report. 2008.

13. Ho MC, Shaw D, Lin SY and Chiu YC. How do disaster characteristics influence risk perception? Risk Analysis, 2008; 28(3):635-643.

14. Heitz C, Spaeter S, Auzet AV and Glatron S. Local stakeholders' perception of muddy flood risk and implications for management approaches: A case study in Alsace (France). Land Use Policy, 2009; 26(2):443-451.

15. Botzen WJW, Aerts JCJH and van den Bergh JCJM. Dependence of flood risk perceptions on socioeconomic and objective risk factors. Water Resources Research, 2009; 45(-.

16. Burby RJ and Wagner F. Protecting tourists from death and injury in coastal storms. Disasters, 1996; 20(1):49-60.

17. Sowby FD. Radiation and Other Risks. Health Physics, 1965; 11(9):879-\&.

18. Starr C. Social benefit versus technological risk. Science, 1969; 165(3899):12321238.

19. Messner F and Meyer V. Flood damage, vulnerability and risk perception Challenges for flood damage research. In: Schanze J, Zeman E and Marsalek J, editor. Flood Risk Management: Hazards, Vulnerability and Mitigation Measures. Dordrecht: Springer; 2006, 149-167.

20. Raaijmakers R, Krywkow $\mathbf{J}$ and van der Veen A. Flood risk perceptions and spatial multi-criteria analysis: an exploratory research for hazard mitigation. Natural Hazards, 2008; 46(3):307-322.

21. Schanze J. A Conceptual Framework for Flood Risk Management Research. In: Schanze J, editor. Flood Risk Management Research - From extreme events to citizens involvement. Proceedings of European Symposium on Flood Risk Management Research (EFRM 2007). Dresden: 2007, 1-10.

22. Slovic P. Perception of Risk. Science, 1987; 236(4799):280-285.

23. Keller C, Siegrist M and Gutscher H. The role of the affect and availability heuristics in risk communication. Risk Analysis, 2006; 26(3):631-639.

24. Terpstra T, Gutteling JM, Geldof GD and Kappe LJ. The perception of flood risk and water nuisance. Water Science and Technology, 2006; 54(6-7):431-439. 
25. Bier VM. On the state of the art: risk communication to the public. Reliability Engineering \& System Safety, 2001; 71(2):139-150.

26. Jacobs L and Worthley R. A comparative study of risk appraisal: A new look at risk assessment in different countries. Environmental Monitoring and Assessment, 1999; 59(2):225-247.

27. Wright $\mathrm{G}$, Bolger $\mathrm{F}$ and Rowe $\mathrm{G}$. An empirical test of the relative validity of expert and lay judgments of risk. Risk Analysis, 2002; 22(6):1107-1122.

28. Burningham $\mathrm{K}$, Fielding $\mathbf{J}$ and Thrush D. 'It'll never happen to me': understanding public awareness of local flood risk. Disasters, 2008; 32(2):216-238.

29. Rowe G and Wright G. Differences in expert and lay judgments of risk: Myth or reality? Risk Analysis, 2001; 21(2):341-356.

30. Siegrist $\mathrm{M}$ and Gutscher H. Flooding risks: A comparison of lay people's perceptions and expert's assessments in Switzerland. Risk Analysis, 2006; 26(4):971-979.

31. Chauvin B, Hermand D and Mullet E. Risk Perception and Personality Facets. Risk Analysis, 2007; 27(1):171-185.

32. Armas I and Avram E. Perception of flood risk in Danube Delta, Romania. Natural Hazards, 2009; 50(2):269-287.

33. Zaalberg R, Midden C, Meijnders A and McCalley T. Prevention, Adaptation, and Threat Denial: Flooding Experiences in the Netherlands. Risk Analysis, 2009; 29(12):1759-1778.

34. Whitmarsh L. Are flood victims more concerned about climate change than other people? The role of direct experience in risk perception and behavioural response. Journal of Risk Research, 2008; 11(3):351-374.

35. Kaiser G, Reese S, Sterr H and Markau H-J. COMRISK subproject 3: Public perception of coastal flood defence and participation in coastal flood defence planning. Interreg III B North Sea Region Programme of the European Union. 2004.

36. Kreibich H, Thieken AH, Petrow T, Muller M and Merz B. Flood loss reduction of private households due to building precautionary measures - lessons learned from the Elbe flood in August 2002. Natural Hazards and Earth System Sciences, 2005; 5(1):117-126.

37. Vanneuville W, De Maeyer P, Maeghe K and Mostaert F. Model the effects of a flood in the Dender catchment based on a risk methodology. Bulletin of the Society of Cartography, 2003; 37(2):59-64.

38. N.N. Oostende onder water. Beernem: De Windroos, 2003.

39. Peacock WG, Brody SD and Highfield W. Hurricane risk perceptions among Florida's single family homeowners. Landscape and Urban Planning, 2005; 73(2-3):120-135.

40. Brody CJ. Differences by Sex in Support for Nuclear-Power. Social Forces, 1984; 63(1):209-228.

41. Grothmann T and Reusswig F. People at risk of flooding: Why some residents take precautionary action while others do not. Natural Hazards, 2006; 38(1-2):101-120.

42. Lindell MK and Hwang SN. Households' perceived personal risk and responses in a multihazard environment. Risk Analysis, 2008; 28(2):539-556.

43. Houts PS, Lindell MK, Hu TW, Clearly PD and Tokuata G. The protective action decision model applied to evacuation during the three Mile Island crisis. International Journal of Mass Emergencies \& Disasters, 1984; 2(1):27-40.

44. Perry RW and Lindell MK. Twentieth Century Volcanicity at Mt. St. Helens: The Routinization of Life Near an Active Volcano. Pullman, WA: Washington State University Press, 1990. 
45. Drabek TE. Disaster warning and evacuation responses by private business employees. Disasters, 2001; 25(1):76-94.

46. Lindell MK and Prater CS. Household Adoption of Seismic Hazard Adjustments: A Comparison of Residents in Two States. International Journal of Mass Emergencies \& Disasters, 2000; 18(2):317-338.

47. Savage I. Demographic Influences on Risk Perceptions. Risk Analysis, 1993; 13(4):413-420.

48. Siegrist $\mathrm{M}$ and Gutscher H. Natural hazards and motivation for mitigation behavior: People cannot predict the affect evoked by a severe flood. Risk Analysis, 2008; 28(3):771-778.

49. Brody SD, Peck BM and Highfield WE. Examining localized patterns of air quality perception in Texas: A spatial and statistical analysis. Risk Analysis, 2004; 24(6):1561-1574.

50. Lindell MK and Perry RW. Household adjustment to earthquake hazard - A review of research. Environment and Behavior, 2000; 32(4):461-501.

51. Arlikatti S, Lindell MK, Prater CS and Zhang Y. Risk area accuracy and hurricane evacuation expectations of coastal residents. Environment and Behavior, 2006; 38(2):226-247.

52. Miceli R, Sotgiu I and Settanni M. Disaster preparedness and perception of flood risk: A study in an alpine valley in Italy. Journal of Environmental Psychology, 2008; 28(2):164-173.

53. Barnett $\mathbf{J}$ and Breakwell GM. Risk perception and experience: Hazard personality profiles and individual differences. Risk Analysis, 2001; 21(1):171-177.

54. Terpstra T, Lindell MK and Gutteling JM. Does Communicating (Flood) Risk Affect (Flood) Risk Perceptions ? Results of a Quasi-Experimental Study. Risk Analysis, 2009; 29(8):1141-1155.

55. Jonkman SN, Vrijling JK and Vrouwenvelder ACWM. Methods for the estimation of loss of life due to floods: a literature review and a proposal for a new method. Natural Hazards, 2008; 46(3):353-389.

56. Green CH, Tunstall SM and Fordham MH. The Risks from Flooding - Which Risks and Whose Perception. Disasters, 1991; 15(3):227-236.

57. Gunst C, Vandenbroucke L and Verhaeghe A. Secondary residences in focus [in Dutch]. West-Vlaanderen Werkt, 2008; 3(14-21.

58. Preacher KJ and Hayes AF. Asymptotic and resampling strategies for assessing and comparing indirect effects in multiple mediator models. Behavior Research Methods, 2008; 40(879-891.

59. Baron RM and Kenny DA. The moderator-mediator variable distinction in social psychological research: Conceptual, strategic, and statistical considerations. Journal of Personality and Social Psychology, 1986; 51):1173-1182.

60. Aiken LS and West SG. Multiple regression: Testing and interpreting interactions. London: Sage Publications, 1991. 